DOI https://doi.org/10.15589/znp2020.3(481).16

УДК 330.46

\title{
METHODOLOGY OF SOLVING FUZZY MULTICRITERIAL PROBLEMS OF OPTIONS SELECTION
}

\section{МЕТОДИКА ВИРІШЕННЯ НЕЧІТКИХ БАГАТОКРИТЕРІАЛЬНИХ ЗАДАЧ ВИБОРУ ВАРІАНТІВ}

\author{
Nelya V. Degtyareva \\ degtyarevanv@fizmatsspu.sumy.ua \\ ORCID: 0000-0001-9590-4915 \\ Yuliya O. Rudenko \\ yango641@ukr.net \\ ORCID: 0000-0003-3162-1216 \\ Volodymyr H. Shamonia \\ shamonawg@gmail.com \\ ORCID: 0000-0002-3201-4090 \\ Olena V. Semenikhina \\ e.semenikhina@fizmatsspu.sumy.ua \\ ORCID: 0000-0002-3896-8151
}

\section{Н. В. Дегтярьова}

кандидат педагогічних наук, доцент кафедри інформатики

Ю. О. Руденко

кандидат педагогічних наук, доцент кафедри інформатики

\section{В. Г. Шамоня}

кандидат фізико-математичних наук, доцент кафедри інформатики

О. В. Семеніхіна

доктор педагогічних наук, професор кафедри інформатики

\section{Makarenko Sumy State Pedagogical University, Sumy \\ Сумський педагогічний університет імені А.С. Макаренка, м. Суми}

\begin{abstract}
Objective: to describe the importance of using multicriterial decision-making methods for a wide range of tasks in different subject areas.

Methodology: Analysis of fuzzy logic methods for developing methods for solving fuzzy multicriterial choice problems Results. The necessity of improving the method of decision-making in the tasks of evaluation and selection of options due to the large dimension of the space of alternatives, the space of criteria for the selection and complexity of calculations is proved.

Scientific novelty. The main stages of the methodology are presented: formation of criteria; determination of membership functions of fuzzy sets on the basis of expert information on pairwise comparisons; ordering options based on the intersection of fuzzy sets of criteria; ranking criteria.

Practical significance. The expediency of using the morphological method, a set of modified algorithms for solving multicriterial selection problems on the basis of the algorithm of pairwise comparisons of T. Saati is shown in the methodology. An example of using the technique in solving an applied problem - choosing the best applicant according to certain criteria. Conclusions are made about the importance of using mechanisms of fuzzy logic, modified algorithms of pairwise comparison technology in multicriterial analysis of different characteristics and the possibility of its implementation as a software module for any multicriterial selection problem.

Key words: decision making, multicriterial, uncertainty, methods of multicriterial decision making; fuzzy multicriterial selection problems; pairwise comparison algorithm; tasks of evaluation and selection of options.
\end{abstract}

Анотація. Мета: описати важливість використання методів багатокритеріального прийняття рішень для широкого спектру завдань з різних предметних галузей.

Методика: Аналізметодів нечіткоїлогікидля розробленняметодикирозв'язування нечітких багатокритеріальних задач вибору варіантів.

Результати. Доведено необхідність вдосконалення методики прийняття рішень в задачах оцінки і вибору варіантів через велику розмірність простору альтернатив, простору критеріїв за якими проводиться вибір та трудомісткість розрахунків.

Наукова новизна. Представлені основні етапи методики: формування критеріїв; визначення функцій належності нечітких множин на основі експертної інформації про парні порівняння; впорядкування варіантів на основі перетину нечітких множин-критеріїв; ранжування критеріїв. 


\section{СУЧАСНИЙ СТАН I РОЗВИТОК ТЕХНОЛОГІЙ №3 2020}

Практична значущість. Показана доцільність використання у методиці морфологічного методу, комплексу модифікованих алгоритмів розв'язання задач багатокритеріального вибору на основі алгоритму парних порівнянь T.Сааті. Наведений приклад використання методики при вирішенні прикладної задачі - вибору найкращого претендента за визначеними критеріями. Зроблено висновки про важливість застосування механізмів нечіткої логіки, модифікованих алгоритмів технології парних порівнянь при багатокритеріальному аналізі різних характеристик і можливість ііі реалізації як програмного модуля для будь-якої задачі багатокритеріального вибору.

Ключові слова: прийняття рішень, багатокритеріальність, невизначеність, методи багатокритеріального прийняття рішень; нечіткі багатокритеріальні задачі вибору; алгоритм парних порівнянь; задачі оцінки і вибору варіантів.

\section{ПОСТАНОВКА ЗАДАЧІ}

У більшості предметних областей зустрічається завдання згрупувати або впорядкувати аналізовані об'єкти, грунтуючись на їх ознаках. Багатокритеріальне прийняття рішень, розпізнавання образів, класифікація, обробка різнорідної інформації - достатньо широке коло завдань, де досліджувані об'єкти характеризуються багатьма різнорідними ознаками, які можуть бути кількісними, якісним або інтервальними. Вирішення таких задач ускладняється їх неформалізованим характером, який важко піддається математичному опису, значною кількістю альтернатив та критеріїв оцінювання.

Спектр застосування багатокритеріальних задач відбору та впорядкування об'єктів занадто широкий від управління будь-якими технічними, фінансовими, логістичними процесами до оцінки їх якісних характеристик. Зокрема, такими задачами $є$ : проведення конкурсного відбору за деякими критеріями; формування банку вакансій за певними характеристиками; профорієнтація учнів; вибір найкращого претендента для отримання нагороди тощо. В усіх зазначених задачах точні результати отримати майже неможливо, можливо лише максимально наблизитися до них.

Для оцінювання альтернатив та можливих наслідків традиційно використовуються складні аналітичні розрахунки, знання фахівців-експертів, засоби сучасних інформаційних технологій. Підвищення вимог до інформаційно-комунікаційних систем, необхідність одночасно враховувати значну кількість кількісних, якісних та інтервальних критеріїв зумовлює необхідність вдосконалення методики прийняття рішень в задачах оцінки і вибору варіантів.

\section{АНАЛІЗ ДОСЛІДЖЕНЬ І ПУБЛІКАЦІЙ}

Вітчизняними і зарубіжними науковцями приділено значну увагу проблемам розв'язання багатокритеріальних задач прийняття рішень у нечіткому середовищі. Перший крок до зближення точності класичної математики з масовою нечіткістю реального світу зробив Л. Заде [1]. Теоретичні основи теорії нечітких множин закладені у роботах Б. Коско, автоpa теореми FAT (Fuzzy Approximation Theorem) [2]. Згідно $з$ цією теоремою будь-яка класична математика може бути апроксимована засобами нечіткої логіки. Технологія прийняття рішень на базі математич- них розрахунків та використання методу попарних порівнянь була розроблена Т. Сааті і отримала назву «Метод аналізу ієрархій» [3]. На класичній технології Т.Сааті було розроблено удосконалені, модифіковані алгоритми аналізу ієрархій, у тому числі і у нечіткому середовищі [4].

Оскільки об'єктивність оцінки в задачах вибору залежить від урахування саме багатокритеріальності, то вона має грунтувавтися на математичному методі отримання цієї величини. Математичним проблемам багатокритеріальності у «розмитих» множинах приділяють увагу Маляр М. [5], Кизим М., Забродський В., Зінченко В., [6] та інші. Автоматизації процесу вибору та варіантного оцінювання приділено увагу Войтко В., Бевз С., Бурбело С. [7] Врахування багатокритеріальності в задачах вибору зумовлює необхідність вдосконалення методики прийняття рішень.

\section{ОСНОВНИЙ МАТЕРІАЛ}

Важливою особливістю реальних задач вибору $\epsilon$ велика розмірність як простору альтернатив, так і простору критеріїв за якими проводиться їх оцінка. Ці особливості збільшують трудомісткість вирішення задач вибору.

3 позицій системного підходу завдання формування вирішення багатокритеріальних задач вибору варіантів можна представити наступним набором інформації

$$
<\mathrm{T}, \mathrm{X}, \mathrm{Q}, \mathrm{A}, \mathrm{F}, \mathrm{G}, \mathrm{L}, \mathrm{M}, \mathrm{N}, \mathrm{C}, \mathrm{P}, \mathrm{S}, \mathrm{D}>\text {, де }
$$

$\mathrm{T}$ - постановка задачі (наприклад, $\mathrm{t}_{1}$-сформувати варіанти і вибрати найкращий варіант системи; $\mathrm{t}_{2}-$ сформувати і вибрати варіант, який найближчий за властивостями до заданого у завданні; $\mathrm{t}_{\mathrm{n}}$-сформувати варіанти і впорядкувати їх набір за ступенем схожості до заданого і т.д.); $\mathrm{X}$ - множина допустимих альтернатив; Q - множина критеріїв оцінювання альтернатив і вибору варіанта системи; А - множина методів вимірювання переваг альтернатив; F - множина допустимих альтернатив, що реалізують функції у множині критеріальних оцінок; $\mathrm{G}$ - система переваг вибраного елементу; L - способи дослідження системи; $\mathrm{M}$ - методи оцінювання варіантів; $\mathrm{N}$ - процедури вибору варіантів; С - вид цільової функції; Р - кількість розглянутих рівнів системи; $\mathrm{S}$ - рівень формалізації постановки і рішення задачі; D - правило, що відображає систему переваг. 
Представимо основні етапи методики:

1 етап. Формування критеріїв, заданих на універсальних множинах варіантів на основі математичного апарату нечіткої логіки,

2 етап: Визначення функцій належності нечітких множин на основі експертної інформації про парні порівняння варіантів за 9-бальною шкалою Т. Сааті [3].

3 етап. Впорядкування варіантів на основі перетину нечітких множин-критеріїв, які відповідають принципу Беллмана-Заде, згідно з яким мета при- йняття рішення про вибір об'єкта і множина допустимих альтернатив розглядаються як рівноправні нечіткі множини універсальної множини альтернатив [8].

4 етап. Ранжування критеріїв методом парних порівнянь і облік отриманих рангів як ступенів концентрацій відповідних функцій належності.

Блок-схема методики представлена на рис. 1.

Особливість реалізованого підходу полягає в тому, що генерація варіантів здійснюється морфологічним методом. Сутність цього методу полягає у розбитті

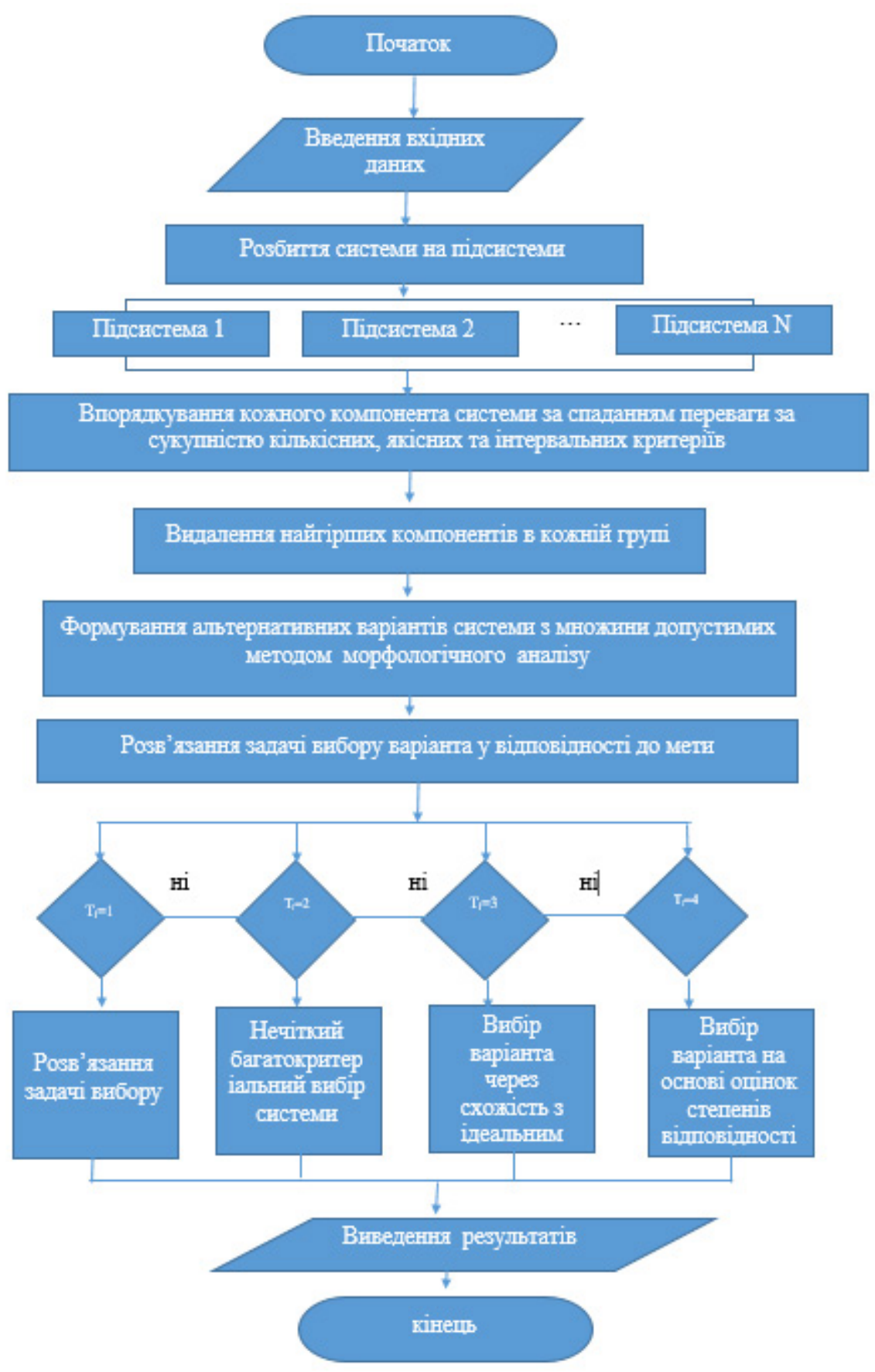

Рис. 1. Узагальнена схема методики формування і вибору варіанта 


\section{СУЧАСНИЙ СТАН I РОЗВИТОК ТЕХНОЛОГІЙ № 3- 2020}

будь-якої задачі на відносно незалежні частини, тобто представлення ii у вигляді матриці з вписаними у кожному рядку частинами [9]. В клітинках матриці вписуються всі альтернативні шляхи вирішення і всі можливі шляхи вирішення.

Необхідність перебору всіх можливих альтернатив вирішення проблеми і вибір кращих рішень проводиться за допомогою комплексу алгоритмів розв'язання задач багатокритеріального вибору. Серед них - модифікований алгоритм впорядкування переваг за схожістю з ідеальним рішенням; алгоритм на основі оцінок необхідного і можливого рівнів відповідності варіантів заданим вимогам та інші.

Критерій $q \in Q$ можна представити у вигляді нечіткої множини $\tilde{q}$, яка задана на універсальній множині $S$ наступним чином

$$
\tilde{q}=\left\{\mu^{\prime}\left(s_{1}\right) / s_{1}, \mu^{\prime}\left(s_{2}\right) / s_{2}, \ldots \mu^{\prime}\left(s_{n}\right) / s_{n},\right.
$$

де $\mu^{\prime}\left(s_{i}\right)$ - степінь належності елементу $s_{i}$ нечіткій множині $\tilde{q}$

Для визначення ступеня належності формуються матриці парних порівнянь варіантів за кожним критерієм, загальна кількість яких дорівнює т. Елемент матриці парних порівнянь $\mathrm{m}_{\mathrm{ij}}$ оцінюється експертами за 9-бальною шкалою Т. Сааті. При наявності властивостей симетричності і транзитивності обчислюються степені належності за формулою 3.

$$
\mu^{l}\left(s_{i}\right)=1 /\left(m_{1 i}^{l}+m_{2 i}^{l} \ldots m_{n i}^{l}\right)
$$

Нечітка множина $\tilde{D}$, необхідна для вибору найкращого варіанту багатокритеріальної задачі визначається за формулою

$$
\tilde{D}=\left\{\operatorname { m i n } _ { l = 1 , m } \left[\mu^{\prime}\left(s_{1)}\right] w 1 / s_{1}, \min _{l=1, m}\left[\mu^{\prime}\left(s_{2}\right] w 2 / s_{2}, \min _{l=1, m}\left[\mu^{\prime}\left(s_{n}\right)\right] w n / s_{n}\right\},\right.\right.
$$

де $w_{1}, w_{2}, \ldots, w_{n}-$ коефіцієнти відносної важливості критеріїв $q_{1}, q_{2}, \ldots, q_{m}$.

Для визначення коефіцієнтів відносної важливосTi $\mathrm{w}_{1}, \mathrm{w}_{2}, \ldots, \mathrm{w}_{\mathrm{n}}$ потрібно сформувати матрицю парних порівнянь важливості критеріїв $q_{l} \in Q$ і скористатися формулою 3.

Отже найкращим варіантів вирішення поставленої задачі є той, який має найбільший степінь належності

$$
\mu_{D}\left(s^{*}\right)=\max \mu_{D}\left(s_{i}\right)
$$

За представленим алгоритмом вибору варіанту в нечітких умовах багатокритеріальної задачі розглянемо приклад: вибір президента школи серед трьох претендентів (учнів). Отже, задача зводиться до порівняння трьох альтернативних варіантів системи $\mathrm{s}_{1}, \mathrm{~s}_{2}, \mathrm{~s}_{3}$. Оцінка ефективності буде відбуватися за такими критеріями: $\mathrm{q}_{1}$ - ораторські здібності; $\mathrm{q}_{2}-$ працездатність; $\mathrm{q}_{3}$ - комунікабельність; $\mathrm{q}_{4}$ - організаційні здібності; q - відповідальність; $\mathrm{q}_{6}$ - творчі здібності.

При експертному порівнянні студентів за критеріями були отримані лінгвістичні судження, представ-

\begin{tabular}{|c|c|}
\hline Критерій & Парні порівняння \\
\hline $\mathrm{q}_{1}$ & $\begin{array}{c}\text { Відсутність переваги } \mathrm{s}_{1} \text { над } \mathrm{s}_{2} \\
\text { Суттєва перевага } \mathrm{s}_{3} \text { над } \mathrm{s}_{1}\end{array}$ \\
\hline $\mathrm{q}_{2}$ & $\begin{array}{c}\text { Майже суттєва перевага } \mathrm{s}_{1} \text { над } \mathrm{s}_{3} \\
\text { Слабка перевага } \mathrm{s}_{2} \text { над } \mathrm{s}_{3}\end{array}$ \\
\hline $\mathrm{q}_{3}$ & $\begin{array}{c}\text { Суттєва перевага } \mathrm{s}_{1} \text { над } \mathrm{s}_{2} \\
\text { Явна перевага } \mathrm{s}_{1} \text { над } \mathrm{s}_{3}\end{array}$ \\
\hline $\mathrm{q}_{4}$ & $\begin{array}{c}\text { Слабка перевага } \mathrm{s}_{2} \text { над } \mathrm{s}_{1} \\
\text { Майже слабка перевага } \mathrm{s}_{3} \text { над } \mathrm{s}_{1}\end{array}$ \\
\hline $\mathrm{q}_{5}$ & $\begin{array}{c}\text { Суттєва перевага } \mathrm{s}_{1} \text { над } \mathrm{s}_{2} \\
\text { Майже явну перевагу } \mathrm{s}_{1} \text { над } \mathrm{s}_{3}\end{array}$ \\
\hline $\mathrm{q}_{6}$ & $\begin{array}{l}\text { Майже суттєву перевагу } s_{1} \text { над } s_{2} \\
\text { Майже слабка перевага } s_{3} \text { над } s_{1}\end{array}$ \\
\hline
\end{tabular}
лені у табл. 1.
Таблиця 1. - Парні порівняння якостей учнів за шкалою Сааті

Відносна важливість критеріїв $\mathrm{q}_{1}-\mathrm{q}_{6}$ визначається за допомогою наступних експертних суджень: майже суттєва перевага $\mathrm{q}_{2}$ над $\mathrm{q}_{1}$; явна перевага $\mathrm{q}_{3}$ над $\mathrm{q}_{1}$; слабка перевага $\mathrm{q}_{3}$ над $\mathrm{q}_{5}$; майже слабка перевага $\mathrm{q}_{4}$ над $\mathrm{q}_{6}$; відсутність переваги $\mathrm{q}_{5}$ над $\mathrm{q}_{6}$.

Для експертних суджень $\mathrm{q}_{1}-\mathrm{q}_{6}$ також будується матриця парних порівнянь для визначення відносної важливості критеріїв. Обчислюються ранги критеріїв. Для нашого прикладу вони наступні: $\mathrm{q}_{1}-\mathrm{q}_{6}: \mathrm{w}_{1}=0.04$; $\mathrm{w}_{2}=0.19 ; \mathrm{w}_{3}=0,33 ; \mathrm{w}_{4}=0.22 ; \mathrm{w}_{5}=0.11 ; \mathrm{w}_{6}=0.11$. Найвищу вагу мають критерії $\mathrm{q}_{3}$ i q дом - це комунікабельність і організаційні здібності претендента). Розраховуємо степені належності елементів нечіткій множині $\tilde{q}$ критеріїв заформулою 2.

$$
\begin{aligned}
& \tilde{q}_{1}=\left\{0,91 / s_{1}, 0,91 / s_{2}, 0,98 / s_{3}\right\}, \\
& \tilde{q}_{2}=\left\{0,88 / s_{1}, 0,83 / s_{2}, 0,68 / s_{3}\right\}, \\
& \tilde{q}_{3}=\left\{0,91 / s_{1}, 0,53 / s_{2}, 0,48 / s_{3}\right\}, \\
& \tilde{q}_{4}=\left\{0,68 / s_{1}, 0,86 / s_{2}, 0,79 / s_{3}\right\}, \\
& \tilde{q}_{5}=\left\{0,97 / s_{1}, 0,81 / s_{2}, 0,79 / s_{3}\right\}, \\
& \tilde{q}_{6}=\left\{0,68 / s_{1}, 0,76 / s_{2}, 0,95 / s_{3}\right\},
\end{aligned}
$$

Після виконання операції перетину $\mathrm{q}_{1}-\mathrm{q}_{6}$ отримуємо за формулою 4

$$
\tilde{D}=\left\{\frac{0,68}{s_{1}} ; \frac{0,53}{s_{2}} ; \frac{0,48}{s_{3}}\right\}
$$

Отримана множина свідчить про суттєву перевагу претендента $\mathrm{s}_{1}$ над претендентами $\mathrm{s}_{2}$ i $\mathrm{s}_{3}$, а також наявності слабкої переваги претендента $\mathrm{s}_{2}$ над $\mathrm{s}_{3}$.

\section{ВИСНОВКИ}

При реалізації розглянутого алгоритму використовується доступна кваліфікованим експертам лінгвістична інформація про якість варіантів у вигляді парних порівнянь. Розглянута процедура вирішення завдання нечіткого багатокритеріального вибору варіантів не вимагає виконання трудоміских обчислень і може бути реалізована як програмний модуль для будь-якої задачі багатокритеріального вибору. 
Використання розробленого методу охоплює широке коло прикладних задач, які мають неформалізовані, абстрактні, «розмиті» статистичні дані і важко піддаються аналізу. Доводиться важливість і доціль- ність застосування механізмів нечіткої логіки, модифікованих методів технології парних порівнянь при багатокритеріальному аналізі різних характеристик через їх універсальність і спрощеність розрахунків.

\section{REFERENCES}

[1]. Zade, L. (1976). Ponyatie lingvisticheskoy peremennoy i ee primenenie k prinyatiyu priblizhennykh resheniy: Per. s angl. N. I. Ringo. M.: Mir. [in Russian].

[2]. Kosko, B. (1986). Fuzzy Cognitive Maps. International Journal of Man-Machine Studies, Vol. 1. pp. 65-75.

[3]. Saati, T. (1993). Prinyatie resheniy. Metod analiza ierarkhiy: Per. s angl. M.: Radio i svyaz. [in Russian]

[4]. Borisov, A.N., Krumberg, O.A., Fedorov, I.P. (1990). Prinyatie resheniy na osnove nechetkikh modeley. Primery ispolzovaniya Riga: Zinatne. [in Russian]

[5]. Maliar, M.M. (2010). Dekompozytsiia zadachi bahatokryterialnoho vyboru. Skhidno-Ievropeiskyi zhurnal peredovykh tekhnolohii. Ser. Matematyka i kibernetyka - fundamentalni i prykladni aspekty. Kharkiv, №6/4(48). S.43-46. [in Ukrainian].

[6]. Kyzym, M. O., Zabrodskyi, V. A., Zinchenko, V. A., Kopchak, Yu. S. (2003). Otsinka i diahnostyka finansovoi stiikosti pidpryiemstva: monohrafiia. Kharkiv: VD «INZhEK». [in Ukrainian].

[7]. Voitenko, V., Bevz, S., Burbelo, S. (2019). Elektronni informatsiini resursy: stvorennia, vykorystannia, dostup: Zbirnyk materialiv Mizhnarodnoi naukovo-praktychnoi Internet-konferentsii. Sumy/Vinnytsia: Niko. [in Ukrainian].

[8]. Bellman, R.E., Zadeh, L.A. (1970). Decision-making in a fuzzy environment. Management Science. Vol. 17, N 4 P. B-141-B-164.

[9]. Zwicky, F. (1998). The morphological method of analysis and construction, Courant, Anniversary Volume.

\section{СПИСОК ВИКОРИСТАНОЇ ЛІТЕРАТУРИ}

[1]. Заде, Л. (1976). Понятие лингвистической переменной и ее применение к принятию приближенных решений: Пер. с англ. Н. И. Ринго / Под ред. Н.Н. Моисеева, С.А.Орловского. М.: Мир.

[2]. Kosko, B. (1986). Fuzzy Cognitive Maps. International Journal of Man-Machine Studies, Vol. 1. pp. 65-75.

[3]. Саати, Т. (1993). Принятие решений. Метод анализа иерархий: Пер. с англ. М.: Радио и связь.

[4]. Борисов, А.Н., Крумберг, О.А., Федоров, И.П. (1990). Принятие решений на основе нечетких моделей. Примеры использования Рига: Зинатне.

[5]. Маляр, М.М. (2010). Декомпозиція задачі багатокритеріального вибору. Східно-Свропейський журнал передових технологій. Сер. Математика і кібернетика - фундаментальні і прикладні аспекти. Харків, №6/4(48). С.43-46.

[6]. Кизим, М. О., Забродський, В. А., Зінченко, В. А., Копчак, Ю. С. (2003). Оцінка і діагностика фінансової стійкості підприємства: монографія. Харків: ВД «ІНЖЕК».

[7]. Войтенко, В., Бевз, С., Бурбело, С. (2019). Електронні інформаційні ресурси: створення, використання, доступ: Збірник матеріалів Міжнародної науково-практичної Інтернет-конференції. Суми/Вінниця: Ніко.

[8]. Bellman, R.E., Zadeh, L.A. (1970). Decision-making in a fuzzy environment. Management Science. Vol. 17, N 4 P. B-141-B-164.

[9]. Zwicky, F. (1998). The morphological method of analysis and construction, Courant, Anniversary Volume. 